\title{
Providing equitable education through personalised adaptive learning and assessment
}

\author{
Punithavathy Palanisamy, Shamini Thilarajah, Zihui Chen \\ National Institute of Education
}

\begin{abstract}
Educators around the globe are striving to promote equity in their classrooms by adopting adaptive learning systems to provide customised learning resources and tools to help the learners achieve mastery at their own pace. This personalised approach goes a long way in closing the divide between students' socioeconomic status and special needs. Over the years, the advancement in technology offers more sophisticated adaptive technologies. It aggregates data such as students' prior knowledge and academic performances to predict and better adapt the learning paths. This paper presents the evaluation of adaptive technologies for personalised learning and the vision of a Personalised Adaptive Learning and Assessment (PALAS) system for Higher Education. This vision could be an imperative piece supporting Singapore's 'National AI Strategy', set to focus on personalised education through adaptive learning and assessment.
\end{abstract}

Keywords: Personalised Learning, Adaptive Technologies, Equity in Education, Educational Technology, Higher Education

\section{Introduction}

In Singapore, we are amid a revolution in education, represented by the shift from one-size-fits-all models of teaching and learning to models that are paced to learning needs and progress, tailored to learning preferences and backgrounds. At the Ministry of Education (MOE) Work Plan Seminar in 2011, the Minister of Education Heng Swee Kiat shared the vision of a learner-centric education. This vision was reiterated at the same platform in 2014 when Mr Heng emphasised the importance of taking a "broad and inclusive" approach and providing "multiple pathways" so that every learner has the opportunity to succeed (Wang, Teng \& Hung, 2014).

In the 2017 Horizon Report by EDUCAUSE, adaptive learning systems were identified as one of the six developments of educational technologies that will have the greatest impact in higher education by presenting new opportunities for adapting instruction to individual learning paths via AI technology (Alexander et al. 2019). To be aligned with our Nation's vision of personalising education, the National Institute of Education (NIE), supported by the Centre of Innovation in Learning (IN-L) has embarked on a study on the capabilities of personalised adaptive learning systems in the current market to assess its integrability in NIE.

\section{Background}

One common challenge that is faced by the faculties in NIE is the insufficient time, space, and resources to address and facilitate the learners with different learning needs. This leads to the arisen need for supplementing/complementing the learners with resources beyond the classroom that are personalised to them. As the learner group in NIE is diverse with multiple needs and goals, the learning delivery should adapt to the varying student learning ability, diverse student backgrounds, and resource limitations.

Centre of Innovation in Learning (IN-L) identified that personalised adaptive learning systems would be able to address this by personalising the learning path (content, activity, diagnostic assessment, feedback, and resources) for individual learners based on their individual ability and inform tutors with legit data on student teachers' learning and performance for a timely intervention. This paper highlights the groundwork done by IN$\mathrm{L}$ in identifying the right system that provides personalised learning for our learners and our findings. 


\section{Defining Personalised Adaptive Learning and Assessment}

\section{Personalised Learning}

In the paper titled "Learning to Adapt: A Case for Accelerating Adaptive Learning in Higher Education" published by Tyton Partners in 2012, personalised learning has been defined as a "pedagogical method or process that draws on observation to inform tailored student educational interventions designed to increase the likelihood of learner success." (Newman, 2013, p4). According to the United States National Education Technology Plan 2017, personalised learning is defined as "instruction in which the pace of learning and the instructional approaches are optimised for the needs of each learner. Learning objectives, instructional approaches, and instructional content (and its sequencing) may all vary based on learner needs." (U.S. Department of Education, 2017, p. 9).

\section{Adaptive Learning}

Adaptive learning relies on technology and data about student performance to adjust and respond with content and methodologies that develop a pathway to the student's mastery of a particular learning objective (Waters, 2014). As an approach to creating a personalised learning experience for students, adaptive learning "takes a sophisticated, data-driven, and in some cases, non-linear approach to instruction and remediation, adjusting to learner's interactions and demonstrated performance level and subsequently anticipating what types of content and resources learners' need at a specific point in time to make progress" (Newman, 2013, p. 4).

\section{Personalised Adaptive Learning and Assessment (PALAS) System}

The recent rise of big data technology gives way for the emergence of personalised adaptive learning due to its capability to record and interpret students' individual characteristics and real-time state in all learning aspects (Peng, Ma \& Spector, 2019). Often called 'personalised learning paths,' questions and objectives are generated algorithmically depending on learner performance, driven by rules hard-coded into the adaptive platform (Brown, 2015). The built-in algorithms process the assessment data, interaction data, and learning behaviour data for each learner in order to create content, activities, feedback and continuous assessment that are adapted and personalised to the real-time context of the individual learner (Hsieh, Le \& Su, 2013).

The delivery of learning via personalised adaptive learning and assessment system involves the following key activities:

- Initial assessment of prior knowledge directs the delivery of content

- Scaffolding approach that addresses the learner's needs with continuous assessments and real-time feedback

- Learning data is constantly fed into the adaptive learning model which allows for the development of an individualised learning pathway for each student and refining relationships between learning objects and concepts (Taylor, et al., 2021).

In addition to using learners' data to determine the learning paths, the adaptive model also provides instructors with the learner data to track student progress, identify problem areas, and intervene (Taylor, 2021; Mavroudi, Giannakos \& Krogstie, 2017). Most personalised adaptive learning and assessment systems also provide learners with a dashboard to better understand their own progress and roadblocks (Mavroudi, Giannakos \& Krogstie, 2017).

The personalised and adaptive nature of assessment and feedback systems is seen as potentially powerful mechanisms for measuring behavioral attributes (e.g., motivation) of students as they engage in the learning process (Xie, et.al. 2019). According to Smith (2016), unlike traditional learning where the instructors find it challenging to identify each learner's understanding of the material, personalised adaptive learning approach continuously provides detailed information to instructors about each learner's progress towards learning objectives. 


\section{Evaluation of Current PALAS Systems}

As a part of our study, we developed a thoughtful rubric that will guide us in assessing the affordances of the platform that might best align with the institutional milieu for successful adoption and implementation. As a first step in developing the evaluation rubric, we have established institutional goals that envisioned the successful implementation of PALAS and capabilities that will help to achieve institutional goals as shown in Figure 1.

Figure 1. PALAS Capabilities mapped with the institutional goals

\begin{tabular}{|c|c|c|c|}
\hline \multirow[b]{2}{*}{$\begin{array}{l}\text { - Provide tools to author } \\
\text { or customise content and } \\
\text { test elements }\end{array}$} & \multicolumn{2}{|c|}{ PALAS Capabilities } & \\
\hline & $\begin{array}{l}\text { - Integrate with existing } \\
\text { LMS seamlessly to acquire } \\
\text { lesson items }\end{array}$ & & \\
\hline $\begin{array}{c}\text { - Assign metadata to the } \\
\text { lesson items (e.g. difficulty, } \\
\text { objective) } \\
\text { - Allow the linking of } \\
\text { prerequisite relationships } \\
\text { between the knowledge items }\end{array}$ & $\begin{array}{l}\text { Tutors can author and } \\
\text { update curriculum and } \\
\text { lesson model based on } \\
\text { the learners } \\
\text { performance data Inst }\end{array}$ & $\begin{array}{r}\text { Personalised content and } \\
\text { assessment aligned with } \\
\text { mastery and learning pace } \\
\text { with respect to the } \\
\text { prior-knowledge }\end{array}$ & $\begin{array}{l}\text { - Target student's starting point } \\
\text { based on prior knowledge } \\
\text { - The sequencing of the } \\
\text { lesson items is timely adapted } \\
\text { to the learner's responses }\end{array}$ \\
\hline $\begin{array}{l}\text { - Identify the lesson areas } \\
\text { with high failure for the } \\
\text { tutor to re-examine } \\
\text { - List the "at-risk" learners } \\
\text { and their challenging areas } \\
\text { for the tutor to intervene }\end{array}$ & $\begin{array}{l}\text { Data-driven } \\
\text { insights that allow } \\
\text { tutors to monitor } \\
\text { student progress and } \\
\text { detect at-risk learner } \\
\text { early }\end{array}$ & $\begin{array}{r}\text { Instructional } \\
\text { support and } \\
\text { feedback offered to } \\
\text { promote self-regulation } \\
\text { of learning }\end{array}$ & $\begin{array}{l}\text { - Detect challenges and } \\
\text { provide just-in-time help } \\
\text { - Learner dashboards that } \\
\text { allow students to track their } \\
\text { progress }\end{array}$ \\
\hline \multicolumn{2}{|c|}{$\begin{array}{l}\text { - Provide insights of the class and } \\
\text { individual learner progress via } \\
\text { individual dashboards }\end{array}$} & $\begin{array}{l}\text { - Feedback on the } \\
\text { readiness of learner to } \\
\text { advance to next level }\end{array}$ & $\begin{array}{c}\text { - Connect learners with class } \\
\text { community and tutors to reach } \\
\text { out for help }\end{array}$ \\
\hline
\end{tabular}

The capabilities shown above were converted into rubric items and each item was assigned with ratings, 1-3 where: (3) indicates that the system has features/tools that can demonstrate the capability, (2) indicates that the system is able to demonstrate the capability with limitations (e.g., not all learning items can be customised) and (1) the system is not able to demonstrate the capability. In the quest to shortlist the PALAS systems, we have remained focused on solutions that automatically respond to learner performance. Our evaluation methods involve testing out the actual platform online (with a trial account) and engaging dialogues with the solutions providers.

\section{Findings}

In our study, we have evaluated different types of adaptive learning solutions which include platforms that offer customisation to a certain extent and others which are wholly developed and self-contained courses. In our evaluation, most platforms scored 2.5 below which indicated that PALAS affordances are met with limitations. Common gaps we found with the platforms we have evaluated include, but are not limited to, are:

- Lack of authoring openness -There are currently few adaptive systems with even rudimentary contentauthoring tools. Most of these systems are one-off build platforms controlled by the vendor, who provides authoring and adaptive course development services.

- Lack of social engagement - Some of the systems consider only static content modules and not peer-topeer learning, group knowledge, and/or any other web source of information.

- Lack of reusability of learning assets - We found that some of the adaptive systems don't have capabilities designed for reusable content in adaptive environments and are not well designed for adding, modifying, and re-creating content.

- $\quad$ Subject-specific design - The systems we have evaluated are designed for and work best in finite subject areas, such as Mathematics. The Adaptive Engine should be broad enough and self-trained to teach other subjects across various disciplines.

- Simplistic design - We received feedback from educators who had tested some of the adaptive learning platforms that the adaptivity level is not up to the skill level of educators. The expectation to have a multi- 
layered adaptivity in terms of content and practice difficulty adjustment, learning loops, and customised feedback style were not met.

The gaps mentioned above can be perceived as challenges in achieving the NIE's goals in personalising education via data driven insights. This has led us to consider an alternative solution of constructing our own PALAS system which could potentially close the gaping holes addressed above and, thus, achieve the goals we set for the PALAS integration.

\section{Design \& Development of a PALAS system for NIE}

We have referred to the articles, published works from other institutions and adaptive learning providers (Pugliese, 2016; Nurjanah, 2016; Dhupia \& Alameen, 2019; Vagale et. al., 2020; O'Sullivan, 2021) to draw the ideas in developing our own PALAS system framework. Our proposed PALAS system will be driven by an AI engine that will contain five main components - Diagnostic Check, Curriculum Model, Learner Model, Predictive Model, and Adaptive Lessons as visualised in Figure 2.

\section{Figure 2. Personalised Adaptive Learning System Framework}

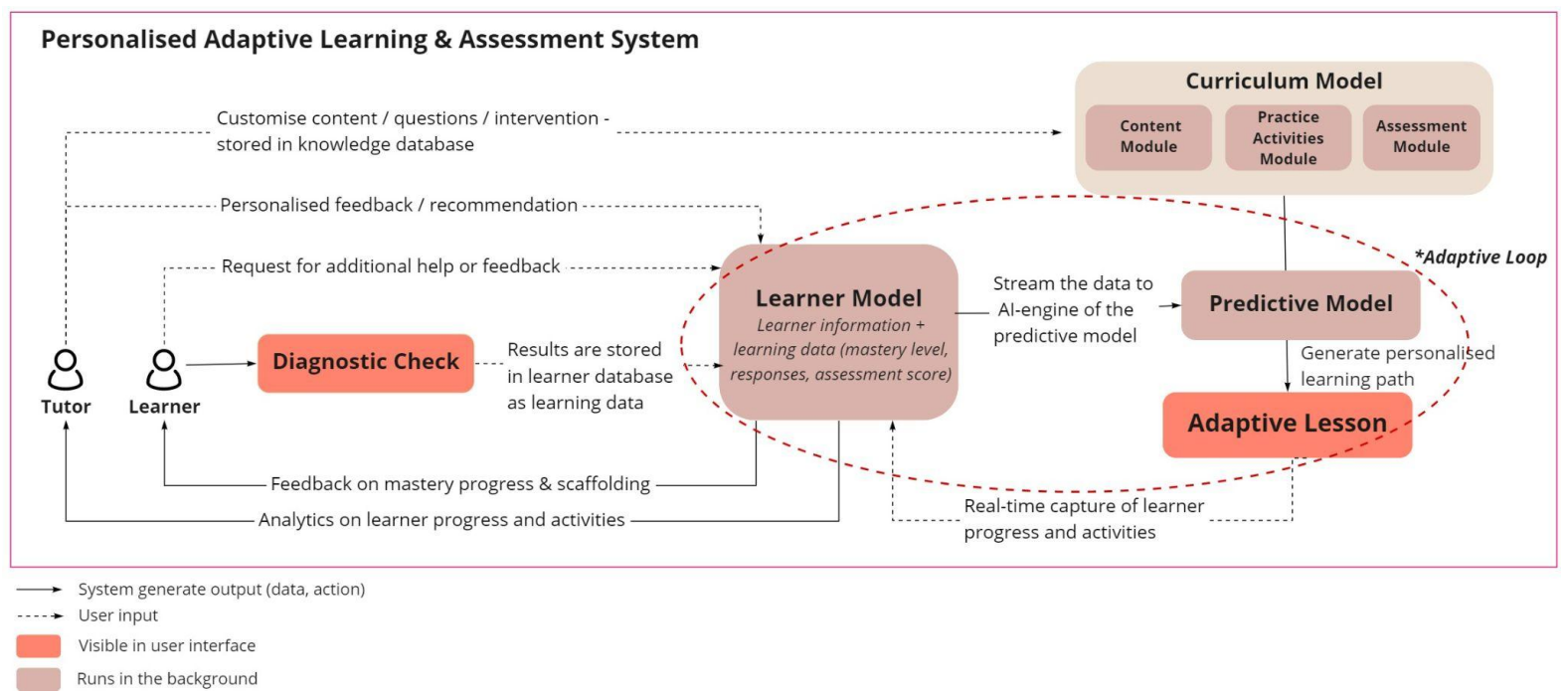

- Diagnostic Check - PALAS will measure the entry-level competency achieved by the learner vs the entrylevel competency required to achieve the lesson's learning objectives. This data helps the system identify the learning areas where the learner needs to improve and areas where the learner has mastered.

- Curriculum Model - PALAS will be built with a curriculum map and content model. A curriculum map is a representation of the knowledge and skills set that a course designer expects the learner to achieve; often derived from 'learning objectives' (O'Sullivan, 2021). A content model contains the metadata about the content such as: difficulty level, probability of guessing, expected time to solve the question. The lesson owner will have full access to build the curriculum map as well as create, upload and customise the test elements and instructional content.

- Learner Model - It contains all the information regarding the learner such as their domain, level of knowledge, learning pattern and other personal information (Dhupia \& Alameen, 2019). It not only saves the information but also tracks the learning records of the users. As a learner completes a lesson, the learner data of the concept or objective that has been worked on will get updated and reflected in both the tutor and learner dashboards.

- $\quad$ Predictive Model - The predictive model employs AI-powered adaptive engine that collects and analyses data in real-time from the learner model and curriculum model and generates personalised learning paths via adaptive lessons (Nurjanah, 2016). It also continuously updates the learner and curriculum model, learning loops and learning path recommendations based on the learner's performance.

- Adaptive Lesson - The adaptive lesson predicts what a learner sees next as he/she interacts with the lesson; from the type of content to the knowledge and skill to be assessed which is also referred as adaptive lesson sequence. The practices and assessments in an adaptive lesson respond with feedback based on the learner's specific response (e.g., hints, review materials on the relevant skill, further scaffolding). 


\section{Conclusion}

To sum up, this paper presents our attempt to define PALAS in our context and study the affordances of adaptive learning systems available. As a first step to realise our goal to develop the institutional PALAS system, we have proposed to develop a Proof of Concept for piloting as a basis for decision-making for the efforts in scaling of PALAS to other faculties. We believe that this pilot study will open the doors for more research and innovations in the area of personalised and adaptive learning via AI technologies in NIE.

\section{References}

Alexander, B., Ashford, R.K., Murph, B.N., Dobbin, G., Knott, J., McCormack, M. (2019). EDUCAUSE Horizon Report 2019. https://library.educause.edu//media/files/library/2019/4/\%202019horizon\%E2\%80\%8Creport.pdf?la=en\&hash=C8E8D444AF372E705F A1BF9D4FF0DD4CC6F0FDD1

Brown, J. (2015). Personalising Post-Secondary Education: An Overview of Adaptive Learning Solutions for Higher Education. https://doi.org/10.18665/sr.221030

Cavanagh, T.L., Chen, B., Lahcen, RAM., Paradiso, JR. (2020). Constructing a design framework and pedagogical approach for adaptive learning in higher education: A practitioner's perspective. https://doi.org/10.19173/irrodl.v21i1.4557

Dhupia, Bhawna \& Alameen, Abdalla. (2019). Adaptive eLearning System: Conceptual Framework for Personalized Study Environment. https://doi.org/10.1007/978-981-15-0108-1_31

Dziuban, C., Moskal, P., Parker, L., Campbell, M., Howlin, C., \& Johnson, C. (2018). Adaptive learning: A stabilizing influence across disciplines and universities. Online Learning, 22(3), 7-39. https://doi.org/10.24059/olj.v22i3.1465

Hsieh, T.C., Lee, M.C. L., \& Su, C.Y. (2013). Designing and implementing a personalized remedial learning system for enhancing the programming learning. Journal of Educational Technology \& Society, 16(4), 3246.

Jones, Mellita M. and McLean, Karen J. (2012). Personalising Learning in Teacher Education through the use of Technology. Australian Journal of Teacher Education, 37(1) https://doi.org/10.14221/ajte.2012v37n1.1

Mavroudi, A \& Giannakos, M \& Krogstie, J. (2017). Supporting adaptive learning pathways through the use of learning analytics: developments, challenges and future opportunities. Interactive Learning Environments. 26. https://doi.org/10.1080/10494820.2017.1292531

Newman, A. (2013). Learning to Adapt: A Case for Accelerating Adaptive Learning in Higher Education. https://tytonpartners.com/library/accelerating-adaptive-learning-in-higher-education/

Nurjanah, D. (2016). Good and Similar Learners' Recommendation in Adaptive Learning Systems. 434-440. https://doi.org/10.5220/0005864304340440

Peng, H., Ma, S. \& Spector, J.M. (2019). Personalised adaptive learning: an emerging pedagogical approach enabled by a smart learning environment. Smart Learning Environment, 6(9). https://doi.org/10.1186/s40561-019-0089-y

Pugliese, L. (2016). Adaptive Learning Systems: Surviving the Storm. EDUCAUSE Review. https://er.educause.edu/articles/2016/10/adaptive-learning-systems-surviving-the-storm

Ryoo, J., Winkelmann, K. (eds.). (2021). Innovative Learning Environments in STEM Higher Education. SpringerBriefs in Statistics. https://doi.org/10.1007/978-3-030-58948-6 2

Smith (2016). Personalized Education Using Adaptive Learning Technology: One Size doesn't have to fit all. Learning and Teaching in Action, 12(1). http://www.celt.mmu.ac.uk/ltia/Vol12Iss1

Taylor, D.L., Yeung, M and Bashet, A.Z (2021). Personalised and Adaptive Learning. In J. Ryoo, K. Winkelmann (Eds.), Innovative Learning Environments in STEM Higher Education, SpringerBriefs in Statistics. https://doi.org/10.1007/978-3-030-58948-6 2

U.S. Department of Education, Office of Educational Technology. (2017). Reimagining the role of technology in education: 2017 national education technology plan update. https://tech.ed.gov/files/2017/01/NETP17.pdf.

Vagale, V., Niedrite, L., Ignatjeva, S. (2020). Implementation of Personalized Adaptive E-learning System. Baltic J. Modern Computing, 8(2), 293-310. https://doi.org/10.22364/bjmc.2020.8.2.06

Wang, L. Y., Teng, S. S., \& Tan, C. S. (2014). Levelling up academically low progress students. NIE Working Paper Series No. 3. Singapore: National Institute of Education.

Waters, J.K. (2014). The Great Adaptive Learning Experiment. https://campustechnology.com/articles/2014/04/16/the-greatadaptive-learning-experiment.aspx. 
Xie, H., Chu, H.-C., Hwang, G.-J., \& Wang, C.-C. (2019). Trends and development in technology-enhanced adaptive/personalised learning: A systematic review of journal publications from 2007 to 2017. Computers \& Education, 140, 103599. https://doi.org/10.1016/j.compedu.2019.103599

Palanisamy P., Thilarajah, S. \& Chen Z. (2021). Providing equitable education through personalised adaptive learning and assessment. In Gregory, S., Warburton, S., \& Schier, M. (Eds.), Back to the Future - ASCILITE '21. Proceedings ASCILITE 2021 in Armidale (pp. 202-207). https://doi.org/10.14742/ascilite2021.0129

Note: All published papers are refereed, having undergone a double-blind peer-review process.

The author(s) assign a Creative Commons by attribution licence enabling others to distribute, remix, tweak, and build upon their work, even commercially, as long as credit is given to the author(s) for the original creation.

() Palanisamy, P., Thilarajah, S., \& Chen Z. 2021 